\title{
Economic Compensatory Method for Thermal Power Unit Joint Wind Power Accommodation Based on Objective Optimization
}

\author{
Wei Zhang ${ }^{*}$, , Chao Qin ${ }^{1}$, Bingbing Zhou ${ }^{2}$, Yanli Huang ${ }^{3}$ and Zhongfu Tan ${ }^{1}$ \\ ${ }^{I}$ School of Economics and Management, North China Electric Power University, Beijing, 102206, P.R. China \\ ${ }^{2}$ State Grid Liaoning Electric Power Supply CO. LTD., Liaoning, 110004, P.R. China \\ ${ }^{3}$ State Grid Shanxi Electric Power Supply CO. LTD., Shanxi, 710048, P.R. China
}

\begin{abstract}
Providing peaking auxiliary for wind power will affect the thermal power generation efficiency and reduce generation economic benefit. To realize the coordinated scheduling optimization of thermal power and wind power, the key problem is the economic compensation of thermal power peaking. In this paper, through the analysis of the influence of wind power on thermal power generation performance and thermal power peak load regulation on abandon wind, an economic compensation model based on objective optimization is established. The example analysis shows that cooperation of thermal power and wind power can improve the wind power accommodation level and unit efficiency, and the economic compensation mechanism can guarantee thermal power unit economic benefit effectively.
\end{abstract}

Keywords: Economic compensatory, objective optimization, thermal power, wind power accommodation.

\section{INTRODUCTION}

With the rapid development of renewable energy and more mature of wind power technology, our country' wind power installed capacity. At the same time, wind power market bother with grid and abandoned wind. According to our country' wind resource distribution characteristic and grid structure, china's wind power generation mainly in northeast, northwest, north of china, which is reverse distribution of electricity load center [1]. Wind has instability, randomness, volatility and so on. It asks higher grid access. Grid considers that its own capabilities and safe operation to wind, sometimes, it will constrain access to part of wind farm power, resulting in serious losses of wind farm power and abandoned wind phenomenon. On the other hand, power structure is single in "three north" regions that wind focuses, and some flexible regulating power account for less $2 \%$ like pumped storage, gas station, especially, due to heating unit than a major in winter, the regions haven' $t$ peaking capacity basically $[2,3]$. However, in European and America, fast track load gas station and pumped storage have high proportion; Spain is $34 \%$ that is 1.7 times of wind power installed capacity; America is up to $47 \%$ that is 13 times of wind power installed capacity, which will support the development of wind power well.

Wind power' characteristics that have inverse load distribution and output instability ask auxiliary power to provide with peaking service, reducing generation output fluctuations impact to electricity system. Literature [4-6] put forward to apply price adjustment mechanisms to stimulate stakeholders' enthusiasm to consume wind power based on

\footnotetext{
*Address correspondence to this author at the School of Economics and Management, North China Electric Power University, Beijing, 102206, P.R. China; Tel: 15210746522; E-mail:qinchao08@163.com
}

abandoned wind power on the spot, and through empirical analysis. Literature [7] analyze wind power consumption facing main problems for solving large-scale wind power consumption problems, and propose low-carbon energy consumptive mechanism conception, and discuss wind power participation market competition viable model and auxiliary service market design in different periods.

Due to guide generation side peaking power to provide with auxiliary service, on the one hand, we need to guarantee generation side enthusiasm through incentives, on the other hand, we need to promote wind power consumption through environment constraint factor. In the scheduling of wind power and thermal power, thermal power peaking ability is calculated according to climbing limit [8]. The scheduling optimization result of coordinating wind power and thermal power is the optimal effect of thermal power assisting wind power consumption under the condition. However, on the one hand, thermal power crowd auxiliary power market share for wind power providing peaking as auxiliary power. On the other hand, it impacts on auxiliary power generation energy efficiency and its economic benefit [9]. Therefore, to achieve thermal power assisting scheduling optimization to wind power, the crucial problem is economic compensatory of thermal peaking. The paper constructs economic compensatory model of thermal power providing auxiliary service based on objective optimization method through analyzing wind power' influence to thermal power generation performance and the influence of thermal power participating peaking degree to abandoned wind power. The paper verifies feasibility of the model through cases considered. 


\section{WIND POWER EFFECTS ON THERMAL POWER GENERATION PERFORMANCE ANALYSIS}

\subsection{Wind Power Effects on Thermal Power Output Analysis}

Wind power output has inverse load distribution characteristic, nighttime load need low periods wind power generation output relatively higher, but daytime load need high periods wind power generation output relatively lower. It definitely increases thermal power units peaking pressure.

Fig. (1) is a region typical day system load and wind power, thermal power output situation. In the system load curve, the maximum load is $2860 \mathrm{MW}$, the minimum load is $1230 \mathrm{MW}$. The difference of maximum and minimum load is $1630 \mathrm{MW}$. Load peak/valley ratio is 2.33 . If there weren't wind power units in system, thermal power units would arrange generation scheduling according to the load level. However, when there are wind power units in the system, due to wind power units crowd numerous generation share of low peak period, resulting in thermal power units generation output equivalent curve having larger drop in valley period and peak period. In the Fig. (1), thermal power equivalent curve maximum load is $2458 \mathrm{MW}$, the minimum load is 204 MW, the difference of maximum and minimum load is 2254 MW. Load peak/valley ratio is 10.07 . Therefore, wind power access power system will increase thermal power units peaking pressures in greater extent.

\subsection{Wind Power Effects on Thermal Power Startup and Shutdown Times Analysis}

After wind power access power system, thermal power units' peaking pressure will increase, and thermal units' startup and shutdown times also will increase. Table $\mathbf{1}$ is thermal power units' startup and shutdown status in including wind power scenarios and excluding wind power scenarios. Under including wind power scenarios, most of thermal power units have startup and shutdown change, but under excluding wind power scenarios, just unit 7, unit 9 and unit10 have startup and shutdown change. From a startup and shutdown cost point of view, all thermal power units' startup and shutdown cost up to 12.92 million RMB in system under including wind power scenarios. All thermal power units' startup and shutdown cost only is 2.82 million RMB in system under excluding wind power scenarios. After wind power access power system, thermal power units' startup and shutdown change frequency increase and start/stop cost have more substantial increase.

\subsection{Wind Power Effects on Thermal Power Generation Coal Consumption Analysis}

Due to wind power demand is higher for spare capacity comparing general power; wind power grid demand also improves for system spare capacity. This means more thermal power units need to depress generated power for providing spare to wind power. As shown in Table 2, under including wind power scenarios, every thermal power units' utilization efficiency lower than use level under excluding wind power scenarios apparently. Under relatively lower units' utilization efficiency, every thermal power units' generation coal consumption also is relatively higher. From generation coal consumption of entire system, thermal units' average generation coal consumption is $324.6 \mathrm{~kg} / \mathrm{kWh}$ under including wind power scenarios, and thermal power units' average generation coal consumption is $326.0 \mathrm{~kg} / \mathrm{kWh}$ under excluding wind power scenarios. Because energy consumption level lower small capacity unit' use level is higher under excluding wind power scenarios, reducing entire energy efficiency level. However, in terms of every unit' generation coal consumption level, generation coal consumption level under wind power scenarios is higher than generation coal consumption level under excluding wind power scenarios.

\section{THERMAL POWER PEAKING EFFECTS ON WIND POWER CONSUMPTION ANALYSIS MODEL}

Wind power grid will increase thermal units' peaking pressure, increase thermal power units' startup and shutdown times, and decrease thermal power units' efficiency level. If lack appropriate compensation mechanism, thermal power units will lack enthusiasm to peaking for wind power. For studying affect level of thermal power participating peaking degree to wind power consumption, the paper estimates wind power consumption potential of sensitive factor that is thermal power units climbing limit and peaking depth under certain value level.

\subsection{Objective Function}

For studying wind power consumption potential under different participation degree of thermal power, we will abandoned wind power minimum as optimization target to

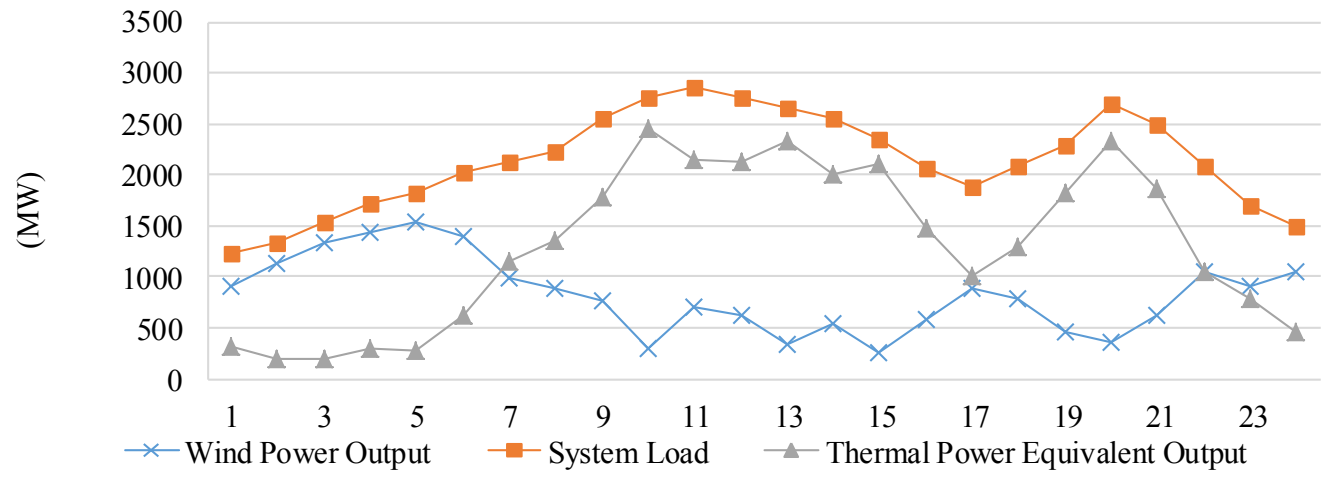

Fig. (1). Distribution of wind power and thermal power output. 
Table 1. Startup and shutdown status of thermal units.

\begin{tabular}{|c|c|c|c|c|c|c|c|c|c|c|c|c|c|c|c|c|c|c|c|c|}
\hline Period & \multicolumn{10}{|c|}{ Including Wind Power Scenarios } & \multicolumn{10}{|c|}{ Excluding Wind Power Scenarios } \\
\hline 1 & 0 & 1 & 1 & 0 & 0 & 0 & ( & & 0 & 0 & 1 & 1 & 1 & 1 & 1 & 1 & 0 & 1 & 0 & 0 \\
\hline 2 & 0 & 1 & 1 & 0 & 0 & 0 & 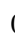 & & 0 & 0 & 1 & 1 & 1 & 1 & 1 & 1 & 1 & 1 & 0 & 0 \\
\hline 3 & 0 & 1 & 1 & 0 & 0 & 0 & ( & & 0 & 0 & 1 & 1 & 1 & 1 & 1 & 1 & 1 & 1 & 0 & 0 \\
\hline 6 & 0 & 1 & 1 & 0 & 0 & 0 & 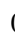 & & 0 & 0 & 1 & 1 & 1 & 1 & 1 & 1 & 1 & 1 & 0 & 0 \\
\hline 7 & 1 & 1 & 1 & 0 & 0 & 0 & 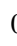 & & 0 & 0 & 1 & 1 & 1 & 1 & 1 & 1 & 1 & 1 & 0 & 0 \\
\hline 8 & 1 & 1 & 1 & 0 & 0 & 0 & & & 0 & 0 & 1 & 1 & 1 & 1 & 1 & 1 & 1 & 1 & 0 & 0 \\
\hline 9 & 1 & 1 & 1 & 1 & 1 & 0 & & & 0 & 0 & 1 & 1 & 1 & 1 & 1 & 1 & 1 & 1 & 0 & 0 \\
\hline 12 & 1 & 1 & 1 & 1 & 1 & 0 & & & 0 & 0 & 1 & 1 & 1 & 1 & 1 & 1 & 1 & 1 & 1 & 1 \\
\hline 13 & 1 & 1 & 1 & 1 & 1 & 0 & & & 0 & 0 & 1 & 1 & 1 & 1 & 1 & 1 & 1 & 1 & 1 & 1 \\
\hline 14 & 1 & 1 & 1 & 1 & 1 & 0 & & & 0 & 0 & 1 & 1 & 1 & 1 & 1 & 1 & 1 & 1 & 1 & 1 \\
\hline 15 & 1 & 1 & 1 & 1 & 1 & 0 & & & 0 & 0 & 1 & 1 & 1 & 1 & 1 & 1 & 1 & 1 & 1 & 1 \\
\hline 16 & 1 & 1 & 1 & 1 & 1 & 0 & & & 0 & 0 & & 1 & 1 & 1 & 1 & 1 & 1 & 1 & 1 & 1 \\
\hline 17 & 1 & 1 & 1 & 1 & 1 & 0 & & & 0 & 0 & & 1 & 1 & 1 & 1 & 1 & 1 & 1 & 1 & 1 \\
\hline 18 & 1 & 1 & 1 & 1 & 1 & 0 & & & 0 & 0 & & 1 & 1 & 1 & 1 & 1 & 1 & 1 & 1 & 1 \\
\hline 19 & 1 & 1 & 1 & 1 & 1 & 0 & & & 0 & 0 & & 1 & 1 & 1 & 1 & 1 & 1 & 1 & 1 & 1 \\
\hline
\end{tabular}

Table 2. Utilization efficiency of thermal power units under different scenarios.

\begin{tabular}{|c|c|c|c|c|c|c|c|c|c|c|}
\hline Scenarios & \multicolumn{10}{|c|}{ Unit (\%) } \\
\hline Including Wind Power & 60.2 & 72.7 & 65.9 & 42.3 & 33.4 & -- & 30.7 & 27.2 & -- & 2.5 \\
\hline Excluding Wind Power & 93.7 & 85.3 & 76.3 & 66.6 & 60.4 & 58.1 & 41.3 & 41.0 & 27.2 & 18.8 \\
\hline
\end{tabular}

Note: “-" presents units aren’t called.

construct wind power and thermal power joint scheduling model.

$$
\min z_{1}=\sum_{t=1}^{T} Q_{a w, t}
$$

In the Eq. (1), $Q_{a w, t}$ is wind power' abandoned electricity at $t$ time.

$Q_{a w, t}=\delta_{t} P_{w}-Q_{w, t}$

In the Eq. (2), $\delta_{t}$ is wind power' maximum equivalent utilization at $t$ time, that is the ratio of power generation accounted for installed capacity; its value size determined by the amount of wind; $P_{w}$ is wind power units' entire installed capacity; $Q_{w, t}$ is wind farm' real-time power generation at $t$ time.

\subsection{Constraints}

To guarantee systems' security and stability, the coordinated scheduling between wind power and thermal power should meet conditions as below. 


\subsubsection{Power Balance Constraints}

To guarantee real-time balance between electricity demand and generation output, the supply and demand of electricity in the system should meet:

$\sum_{i=1}^{I} u_{i, t} Q_{i, t}\left(1-\theta_{i}\right)+Q_{w, t}\left(1-\theta_{w}\right)=G_{t} /(1-l)$

In the Eq. (3), $u_{i, t}$ is unit $i$ ' startup and shutdown state variables at $t$ time. If unit $i$ was startup state at $t$ time, the variable would be 1 . If unit $i$ was shut down state at $t$ time, the variable would be $0 . Q_{i, t}$ is thermal power unit $i$ 's generation at $t$ time; $\theta_{i}$ is unit $i$ 's power consumption rate; $G_{t}$ is real-time electricity demand of system load; $l$ is line loss rate.

\subsubsection{System Generation Spare Constraints}

To guarantee real-time balance of system power, thermal power units' generation output should meet a certain adjusted margin:

$$
\begin{aligned}
& \sum_{i=1}^{I} u_{i, t}\left(Q_{i, t}^{\max }-Q_{i, t}\right)\left(1-\theta_{i}\right) \geq R_{t}^{u s r} \\
& Q_{i, t}^{\max }=\min \left(u_{i, t-1} \overline{Q_{i}}, Q_{i, t-1}+\Delta Q_{i}^{+}\right) \cdot u_{i, t-1} \\
& R_{t}^{u s r}=\beta_{c} \sum_{i=1}^{I} Q_{i, t}+\beta_{w} Q_{w, t}
\end{aligned}
$$

The Eqs. (4)-(6) is system' up rotation spare constraints. $Q_{i, t}^{\max }$ is unit $i$ 's maximum possibly output at $t$ time; $R_{t}^{u s r}$ is system' up rotation spare constraints; $\bar{Q}_{i}$ is unit $i$ 's installed capacity; $\Delta Q_{i}^{+}$is unit $i$ 's up generation climbing rate; $\beta_{c}$ is thermal power units' generation spare coefficient; $\beta_{w}$ is wind power units' generation spare coefficient.

$$
\begin{aligned}
& \sum_{i=1}^{I} Q_{i, t}\left(Q_{i, t}-Q_{i, t}^{\min }\right)\left(1-\theta_{i}\right) \geq R_{t}^{d s r} \\
& Q_{i, t+1}^{\min }=\max \left(u_{i, t} Q_{i}, Q_{i, t}-\Delta Q_{i}^{-}\right) \cdot u_{i, t} \\
& R_{t}^{d s r}=\beta_{w} Q_{w, t}
\end{aligned}
$$

The Eq. (7)-(9) is system' up rotation spare constraints. $Q_{i, t}^{\min }$ is unit $i$ 's maximum possibly output at $t$ time; $R_{t}^{d s r}$ is system' up rotation spare constraints; $Q_{i}$ is unit $i$ 's installed capacity; $\Delta Q_{i}^{-}$is unit $i$ 's up generation climbing rate.

\subsubsection{Thermal Power Units' Real-Time Generation Power Constraints}

Thermal power units' real-time generation output is limited to unit installed capacity and minimum generation output, as below:

$u_{i, t} \underline{Q_{i}} \leq Q_{i, t} \leq u_{i, t} \overline{Q_{i}}$

\subsubsection{Unit Climbing Rate Constraints}

Units' generation output change is constrained in adjacent period, should meet:

$\Delta Q_{i}^{-} \leq Q_{i, t}-Q_{i, t-1} \leq \Delta Q_{i}^{+}$

\subsubsection{Unit Startup and Shutdown Time Constraints}

Units' continuous startup and shutdown time constraints as below:

$$
\begin{aligned}
& \left(T_{i, t-1}^{\text {on }}-M_{i}^{\text {on }}\right)\left(u_{i, t-1}-u_{i, t}\right) \geq 0 \\
& \left(T_{i, t-1}^{\text {off }}-M_{i}^{\text {off }}\right)\left(u_{i, t}-u_{i, t-1}\right) \geq 0
\end{aligned}
$$

The Eq. (12) is unit $i$ 's the shortest startup time constraints; $T_{i, t-1}^{\text {on }}$ is unit $i$ 's operation time at $t-1$ time; $M_{i}^{\text {on }}$ is the unit' the shortest operation time. The formula (13) is unit $i$ 's the shortest shutdown time constraint; $T_{i, t-1}^{\text {off }}$ is unit $i$ 's shutdown time at $t-1$ time; $M_{i}^{\text {off }}$ is the unit' the shortest shutdown time.

\subsubsection{Wind Power Output Constraints}

Wind power units' real-time power output is limited to wind farm' the amount of wind, should meet:

$$
Q_{w, t} \leq \delta_{t} P_{w}
$$

\section{WIND POWER ECONOMIC COMPENSATORY MODEL TO THERMAL POWER}

We can know that wind power grid will impact thermal power economic benefit though analyzing. For promoting thermal power units participate coordinating wind power consumption, the next content will research around thermal power units economic manner.

\subsection{Peaking Auxiliary Services Economic Compensation}

After wind power access into electricity system, thermal power units' equivalent output curve will improve than fluctuation level of system load curve. In the low stage of wind power output, thermal power units will guarantee system equilibrium. With thermal power units' generation output level gradually reduces, thermal power units' generation energy efficiency also decrease. Therefore, thermal powers units must increase auxiliary service costs to compensate generation costs resulting from thermal power peaking.

Peaking auxiliary services compensatory according to units' generation coal consumption situation before and after the wind power access into system, the generation coal consumption level is related to units' load factor. Therefore, we need research thermal power units' load factor before and after the wind power access into system.

With respect to units' energy efficiency level before wind power access into system, through the next optimization model:

$$
\max z_{2}=\pi_{c}
$$




$$
\left\{\begin{array}{l}
\sum_{i=1}^{I} u_{,} Q_{i, t}\left(1-\theta_{i}\right)=G_{t} /(1-I) \\
\text { Formula }(4)-(13)
\end{array}\right.
$$

Solving above model may get real-time generation power $Q_{i, t}^{*}$ of thermal power units under system profit maximization before wind power access into system, system average load factor is:

$\eta_{1}=\frac{\sum_{i=1}^{I} \sum_{t=1}^{T} Q_{i, t}^{*}}{\sum_{i=1}^{I} \sum_{t=1}^{T} \overline{Q_{i}}}$

Every unit' generation coal consumption level under load factor $\eta_{1}$ is:

$$
\operatorname{Coal}_{1, i}=f_{i}\left(\eta_{1} \overline{Q_{i}}\right) / \eta_{1} \overline{Q_{i}}
$$

System average coal consumption level is:

$$
\text { Coal }_{1}=\frac{\sum_{i=1}^{I}\left(\overline{Q_{i}} \cdot \operatorname{Coal}_{1, i}\right)}{\sum_{i=1}^{I} \overline{Q_{i}}}
$$

With respect to units' energy efficiency level after wind power access into system, through the next optimization model:

$$
\begin{aligned}
& \max z_{3}=\pi_{c}+\pi_{w} \\
& \left\{\begin{array}{l}
\sum_{i=1}^{I} u_{i, t} Q_{i, t}\left(1-\theta_{i}\right)+Q_{w, t}\left(1-\theta_{w}\right)=G_{t} /(1-I) \\
\text { Formula }(4)-(14)
\end{array}\right.
\end{aligned}
$$

Solving above model may get real-time generation power $Q_{i, t}^{* * *}$ of thermal power units under system profit maximization before wind power access into system, system average load factor is:

$$
\eta_{2}=\frac{\sum_{i=1}^{I} \sum_{t=1}^{T} Q_{i, t}^{* *}}{\sum_{i=1}^{I} \sum_{t=1}^{T} \overline{Q_{i}}}
$$

Every unit' generation coal consumption level under load factor $\eta_{2}$ is:

$$
\operatorname{Coal}_{2, i}=f_{i}\left(\eta_{2} \overline{Q_{i}}\right) / \eta_{2} \overline{Q_{i}}
$$

System average coal consumption level is:

$$
\mathrm{Coal}_{2}=\frac{\sum_{i=1}^{I}\left(\overline{Q_{i}} \cdot \operatorname{Coal}_{2, i}\right)}{\sum_{i=1}^{I} \overline{Q_{i}}}
$$

(3) Economic compensation costs of peaking unit output after wind power access into system is:

$$
\overline{F_{T F}}=p_{\text {coal }}\left(\operatorname{Coal}_{2}-\text { Coal }_{1}\right)
$$

In the Eq. (25), $p_{\text {coal }}$ is standard coal unit price.

If system total peaking output after access into system is $L$, then, thermal power should get peaking auxiliary service cost for wind power peaking is:

$$
F_{T F}=\overline{F_{T F}} \cdot L
$$

\subsection{Spare Auxiliary Service Economic Compensation}

Wind power output level are decided by the amount of wind, therefore, wind power output characteristic have intermittent, uncertainty. System spare capacity which wind power output provide after wind power access to system will be higher than before wind power access to system. However, according to difference reserve coefficient of wind power and thermal power units, we can obtain newly added power reserve capacity after wind power access to electricity system:

$$
\Delta R=\sum_{i=1}^{T} Q_{w, t}\left(\beta_{w}-\beta_{c}\right) / T
$$

In the Eq. (27), $Q_{w, t}$ is wind power actual output at $t$ moment; $\beta_{w}, \beta_{c}$ is spare coefficient of wind power and thermal power respectively.

Assumed to the installed capacity price of thermal power units is $I$, the sharing coefficient at corresponding period is $k$, so thermal power newly incremental costs which wind power provide spare auxiliary service is:

$F_{T F}=k \cdot I \cdot \Delta R$

\section{CASES CONSIDERED}

\subsection{The Impact of Wind Power Consumptive for Thermal Power Units' Different Peaking Depth}

The thermal power units' depth peaking will decrease energy efficiency level of thermal power units. Therefore, assuming every units' the minimum power output level improve $0 \%, 5 \%, 10 \%$ respectively according to the size of the total installed capacity, and carrying out optimization of wind power consumptive according to this, optimization results are shown in Table $\mathbf{3}$.

Contrast to different scenarios optimization results, with the decrease of thermal power units' peaking depth, the ability of the system to wind power peaking will decrease, system wind power consumptive maximum potential will reduce, and wind power abandoned wind will increase. In the situation of thermal power units minimum generation output unchanged, wind power units' abandoned wind rate is $8.6 \%$; when thermal power units minimum generation output improve 5\%, wind power units' abandoned wind rate will increase to $9.1 \%$, the amount of abandoned wind increases 114.5 MWh; However, when thermal power units' minimum generation output improve $10 \%$, wind power units' abandoned wind rate will increase to $9.2 \%$, the amount of abandoned wind increase 125.1 MWh. 
Table 3. Dispatching optimization result of power system under different scenarios.

\begin{tabular}{|c|c|c|c|c|c|c|}
\hline \multirow{2}{*}{ Scenarios } & \multicolumn{3}{|c|}{ Wind Power } & \multicolumn{3}{c|}{ Thermal Power } \\
\cline { 2 - 7 } & $\begin{array}{c}\text { Generating } \\
\text { Capacity (MWh) }\end{array}$ & $\begin{array}{c}\text { Electrical } \\
\text { Proportion (\%) }\end{array}$ & $\begin{array}{c}\text { Abandoned Wind } \\
\text { Rate (\%) }\end{array}$ & $\begin{array}{c}\text { Generating } \\
\text { Capacity (MWh) }\end{array}$ & $\begin{array}{c}\text { Electrical } \\
\text { Proportion (\%) }\end{array}$ & $\begin{array}{c}\text { Coal Consumption } \\
\text { (kg/MWh) } \\
\text { (Thousand } \\
\text { Yuan) }\end{array}$ \\
\hline \hline 1 & 20244.9 & $38.6 \%$ & $8.6 \%$ & 33525.4 & $61.4 \%$ & 354.2 \\
\hline 2 & 20130.5 & $38.4 \%$ & $9.1 \%$ & 33649.5 & $61.6 \%$ & 341.2 \\
\hline 3 & 20119.8 & $38.4 \%$ & $9.2 \%$ & 33631.6 & $61.6 \%$ & 353.1 \\
\hline
\end{tabular}

In contrast, with wind power output decrease, thermal power units' market share will gradually increase; In addition, with the decline of peaking depth, thermal power units' generation use efficiency will improve, units of electricity coal consumption will decrease gradually. In the situation of thermal power units' minimum generation output unchanged, coal consumption of thermal power units is $354.2 \mathrm{~kg} / \mathrm{MWh}$; When thermal power units' minimum generation output increase $5 \%$, coal consumption of thermal power units reduce to $353.1 \mathrm{~kg} / \mathrm{MWh}$; However, when thermal power units' minimum generation output increase $10 \%$, thermal power units' coal consumption decrease to $350.5 \mathrm{~kg} / \mathrm{MWh}$, units of coal consumption cumulatively reduce $3.7 \mathrm{~kg} / \mathrm{MWh}$.

\subsection{The Impact of Wind Power Consumptive for Thermal Power Units' Different Climbing Limit}

Frequent adjustments of thermal power units' generation output will harm power equipment, due to extend the useful life of equipment, thermal power units will as much as possible to reduce power output amplitude adjustment. Therefore, thermal power units' climbing limit as sensitive factor, research maximum potential of wind power consumptive under different value level. Assuming thermal power units' climbing limit reduces $0 \%, 10 \%, 20 \%$ respectively (scenario 4-6), optimization results as shown in Table 4.

Contrast optimization results of different scenarios, with thermal power units' climbing limit decrease, systems' capacity for wind power has declined, systems' maximum potential to consume win power also is declined, but wind power abandoned wind rate will rise. Under thermal power units' climbing limit unchanged, wind power units' abandoned wind rate is $8.6 \%$; when thermal power unit' climbing limit reduces $10 \%$, wind power units' abandoned wind rate improve to $8.9 \%$, the amount of abandoned wind power will increase 59.3 MWh. However, when thermal power units' climbing limit reduce to $20 \%$, wind power units' abandoned rate further improve to $9.1 \%$, the amount of abandoned wind power increase to $113.7 \mathrm{MWh}$.

In contrast, with wind power output decrease, thermal power units' grid electricity proportion of the system total electricity will improve gradually; in addition, with the decrease of peaking amplitude, thermal power units' use efficiency will increase during generating, coal consumption of units of electricity have downward trend. Under thermal power units' climbing limit unchanged, thermal power units' coal consumption is $354.2 \mathrm{~kg} / \mathrm{MWh}$; when thermal power units' climbing limit increase $10 \%$, thermal power units' coal consumption reduce to $350.2 \mathrm{~kg} / \mathrm{MWh}$; when thermal power units' climbing limit improve to $20 \%$, thermal power units' coal consumption further decrease to $347.6 \mathrm{~kg} / \mathrm{MWh}$, coal consumption of units of electricity cumulative reduction $6.6 \mathrm{~kg} / \mathrm{MWh}$.

Standing in the position of the thermal power units' interests, on the one hand, controlling peaking depth and amplitude help to increase the share of generation electricity, thereby increasing their economic benefits; on the other hand, it will help to increase generation energy efficiency, reduce the amount of generation coal consumption of units of electricity, and to decrease units of generation costs. Therefore, driven by the interests, it is difficult to ensure thermal power units' enthusiasm for wind power peaking.

\subsection{Peaking Ancillary Services Economic Compensation Measure}

We will optimize for model (15) and (19) respectively, calculating the objective function' optimal generation output of each unit at each time. According to Eq. (16), Eq. (20), solve thermal power units' load factor before and after to access to wind power. Thermal power units' average load factor before to access to wind power is 0.67 and 0.43 through measuring.

Table 4. Another group dispatching optimization result of power system under different scenarios.

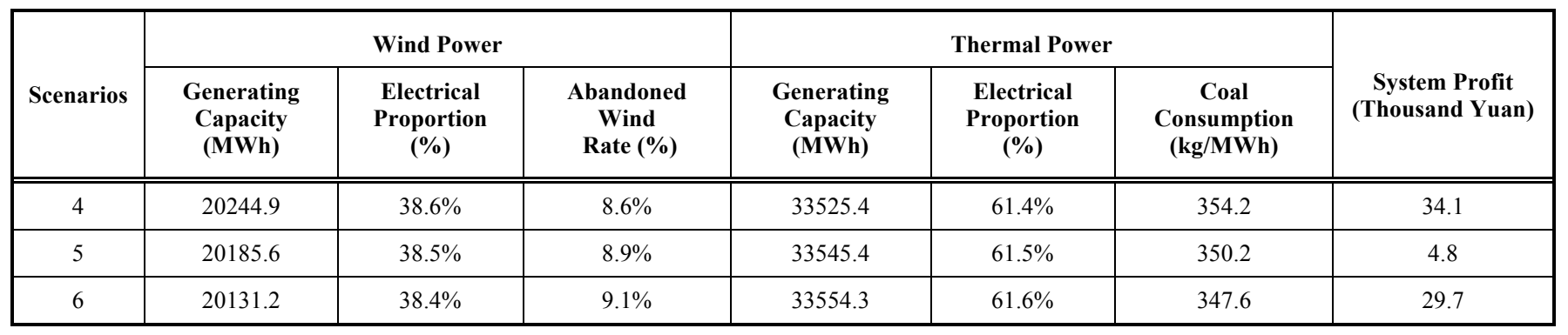


Table 5. Coal consumption rate of thermal units before and after wind power integration.

\begin{tabular}{|c|c|c|c|c|c|c|c|c|c|c|}
\hline Scenarios & \multicolumn{10}{|c|}{ Unit (kg/MWh). } \\
\hline Excluding Wind Power & 321 & 329 & 341 & 349 & 356 & 360 & 362 & 376 & 389 & 374 \\
\hline
\end{tabular}

Combined units' consumption parameters, we calculate each unit's average generation coal consumption level under corresponding load factor respectively, as shown in Table $\mathbf{5}$.

Combined Eq. (18), Eq. (22), we can solve thermal power units' average generation coal consumption rate under corresponding load level before and after to access to wind power respectively is $332.9 \mathrm{~kg} / \mathrm{MWh}, 347.4 \mathrm{~kg} / \mathrm{MWh}$. According to Eq. (23), we can solve peaking auxiliary services fee of unit energy is 8.7 yuan/MWh. According to thermal power units' generation capacity $35274.8 \mathrm{MWh}$ after access to wind power, wind power require a total payment 306.9 thousand yuan for thermal power units as peaking auxiliary services fee.

\subsection{Reserve Service Financial Compensation Measure}

After access to wind power to electricity system, under the goal of system profit maximization, wind power' average output is $826.7 \mathrm{MW}$, according to wind power and thermal power units $15 \%$ and $10 \%$ spare coefficient, electricity system new average spare capacity after access to wind power is $41.3 \mathrm{MW}$. According to thermal power units 4.2 million yuan/MW cost level and 1.85E-4 apportionment factor, wind power has to pay thermal power 32.1 thousand yuan reserve service fees in typical day.

\section{CONCLUSION}

Joint scheduling between general thermal power and wind power on generation side can slow down volatility of wind power output, but some environment policy of generation side will break the equilibrium of the existing market share, wind power get additional power quota with the advantage on its environment values, thus further solve wind power abandoned wind problem, but will affect the economic efficiency of general thermal power. On the base of analysis the impact of wind power to thermal power generation performance and the degree of thermal power participation peaking, the paper established thermal power auxiliary services economic compensation model based on objective optimization methods. The cooperation between wind power and thermal power on the generation side can improve the level of wind power consumptive through cases considered, and further expand the use efficiency of wind power units. At the same time, the economic compensation mechanism can protect the economic profit of thermal power units effectively.

\section{CONFLICT OF INTEREST}

The authors confirm that this article content has no conflict of interest.

\section{ACKNOWLEDGEMENTS}

Declared none.

\section{REFERENCES}

[1] Melbom, P. Trading wind power at the nordic power pool. Renewable Energy, 1999, 16(1-4), 878-881.

[2] Lund, H.; Mathiesen, B.V. Energy system analysis of $100 \%$ renewable energy systems-the case of Denmark in years 2030 and 2050. Energy, 2009, 34(5), 524-531.

[3] Blarke, M.; Lund, H. The effectiveness of storage and relocation options in renewable energy systems. Renewable Energy, 2008, 33(7), 1499-1507.

[4] Porter, K.; Fink, S. Examples of Wind Curtailment. Energy Foundation Meeting on Wind Integration, Beijing: 2010.

[5] Morthorst, P.E. Renewable Energy and a Green Certificate Market World Renewable Energy Congress VI, 2000, 673-676.

[6] Fink, S.; Mudd, C.; Porter, K.; Morgenstern B. Wind Energy Curtailment Case Studies May 2008-May 2009. National Renewable Energy Laboratory (NREL/SR-550-46716): 2009.

[7] Lü, Q.; Wang, W.; Han, S.; Yuan, S.; Zhang, J.; Li, W. A new evaluation method for wind power curtailment based on analysis of system regulation capability. Power Syst. Technol., 2013, 37(7), 18.

[8] Wang, Q. Update and empirical analysis of domestic and foreign wind energy curtailment. East China Elec. Power, 2012, 40(3), 378-381.

[9] Porter K, Rogers J, Wiser R. Update on Wind Curtailment in Europe and North America. Beijing: Consultants to the Center for Resource Solutions 2011. 